\title{
Uma provável ética na antifesta: união, compromisso e contraponto entre vida, política e narração em Glosa, de Juan José Saer
}

Breno Anderson Souza de Miranda

Mestre em História (História e Culturas Políticas) UFMG; mestrando em Letras Estudos

Literários / UFMG

\begin{abstract}
RESUMO
A antifesta em Saer seria utopia da lembrança de um momento antecipatório do que estaria por vir. Lá, militantes e futuros guerrilheiros de esquerda mostrariam seus medos e desejos pelo mais banal e prosaico. Esta é a história que Leto e Matemático não conseguem recuperar, mas que os marcará como restos e possibilidades da experiência.
\end{abstract}

PalaVRas-Chave

Memória, ética, política, estética, guerrilha

\section{NARRATIVA, ENREDO E OBRA EM PREPONDERÂNCIA MINIMALISTA}

O vasto trabalho crítico e ficcional de Juan José Saer não poderia isentar-se de um comprometimento ético, não pelo viés de um afunilamento ou achatamento de alguma ideologia ou pela publicização de nítidos contornos políticos, e sim pelos desdobramentos das presenças e/ou silêncios de uma postura ético-estética que recusaria a vulgaridade do instantâneo-prosaico da cultura de massas, ao mesmo tempo que se contraporia às pretensões de totalidade do "grande” romance realista ou ideológico do século 19. Haveria nítidas separações, fronteiras ou diálogos naquilo que o próprio Saer denominara como "narraçãoobjeto” $^{\text {1 }}$ de possibilidades recíprocas entre conhecimento, criação, percepção e leitura? Nossa

\footnotetext{
1 "Narração-objeto" é um termo caro a Juan José Saer, algo parecido como um entreposto entre narrativa e objeto palpável. "Es posible afirmar que, de manera implícita o explícita, la noción de objeto está en el centro de todo relato de ficción. (...). Al mismo tiempo que objeto verbal, el relato es también objeto mental, y vive en la memoria y en la imaginación de sus destinatarios liberado de su condición verbal. (...). Toda narración tiende a ser única, y esa individuación se produce gracias a la proliferación en su interior de elementos particulares en detrimento de los invariantes de construcción y de género. En el caso inverso, el respeto de esos invariantes empobrece el tejido de figuraciones particulares (...) y transforma el relato en una especie de producto industrial”. SAER. La narración-objeto, p. 17, 24, 25.
} 
proposta aqui não seria chegar a um apontamento claramente delimitado sobre qualquer ponto de Glosa de Saer e nem falar de qualquer totalidade da obra. A narrativa de Saer em Glosa remete-nos aos atos da fala e do acontecimento (que é minimalista, como um simples passeio por alguns quarteirões) e tende a ocupar toda a extensão da obra, como movimento. Assim, discorrer sobre o substrato mínimo anticausal e fragmentário que une a glosa das personagens ou sobre qualquer ponto da caminhada seria simultaneamente discorrer sobre a longa extensão da narrativa. Também em Glosa nada seria mais relevante que as tessituras do enredo. Centrar-se na obra e no enredo afasta-nos de prerrogativas teóricas ou culturalistas exteriores que se imporiam sobre nossa perspectiva, que seria justamente adentrar na composição da possibilidade/impossibilidade da narrativa, tão cara a Saer.

Conjuntamente com a narrativa, forma e experiência, experimentação estética e memória interligam-se em Glosa para que se conte o passado recente da Argentina. Mas ela não poderia ser escrita para isso. Não podemos impor-lhe essa exigência. Memórias estão em Glosa, não podemos negar, porém há também os silêncios e as impossibilidades de recontálas, de trazê-las para o papel. O narrador do romance joga com isso o tempo todo, em uma incessante repetição que chega ao fastio e à náusea. O que seria mais relevante: tentar narrar um fato cotidiano que já passou, como uma festa ou reunião de amigos, ou a dura história de perseguições, desaparecimentos e torturas da ditadura militar argentina? Haveria alguma intenção de nivelar essas narrativas, colocá-las no mesmo patamar?

No caso de Glosa, parece que tudo estaria ali para incomodar um leitor pausterizado, que esperaria um viés volátil do acontecido. O romance de Saer não seria a simples representação de alguma história dos vencidos, narrada de uma maneira superficial pelo testemunho ocular de quem vivenciou (ou vivenciaria) fatos sórdidos de uma época sombria. Como já demonstrou demasiadamente a crítica, ${ }^{2}$ o narrador mexe com a possibilidade/impossibilidade da narrativa e esta parece ser uma das principais marcas de seu estilo - uma regressão abismal e negativa (?) ao reencontro com o fato, que não poderá ser recontado tal qual aconteceu, ou esperariam que tivesse acontecido. Não haveria a "grande narrativa” da "História heroica” em Glosa, mesmo que esta fosse uma ficcionalização, aliás, a ficção não se prestaria a grandes projetos utópicos. Algum leitor esperaria uma mera vitimização, entretanto as personagens de Glosa demonstram uma pluralidade de vivências e

\footnotetext{
${ }^{2}$ Beatriz Sarlo cita o importante trabalho sobre a "posibilidad de narrar" em Saer de María Teresa Gramuglio, "Juan José Saer, el arte de narrar” publicado em Punto de Vista, n. 6, jul. 1979. SARLO. Narrar la percepción, p. 283.
} 
expectativas. Ressentimentos antigos teimariam em prevalecer sobre o improvável dos sonhos e iriam além de um vir-a-ser concreto de fabulosos e compensatórios projetos utópicos?

As versões, as percepções e memórias sobre a realidade seriam múltiplas, assim como são infinitas suas interpretações. O narrador coloca a memória em joguete; em estreita ligação incerta com o futuro? As personagens principais do romance, Ángel Leto e Matemático, usam e abusam de tentativas de lembranças, de lembranças de outros, por sua vez. Uma importante centralidade na tessitura esgarçada da obra estaria em sua escritura lacunar e em sua imprecisão. Vazios, silêncios, interditos abrem-se a todo o momento no texto e são elementos da composição de uma antimemória, ou do relato sobre ela, ou ainda do fazer presente uma história que não consegue alcançar a totalidade das experiências vividas. Leto e Matemático são parte de um elenco maior de jovens amigos. Alguém diria que os jovens viveriam mais intensamente. Poderíamos até ressaltar que o espírito aventuresco não faltaria ao romance entenda-se vontade de movimento. Não seria à toa que as personagens caminham sem parar durante toda a obra. A rua, as calçadas, os buracos seriam ocasiões para tropeços e quedas, mas elas continuam sempre em pé e andando. Incansáveis andantes e não menos pensantes. $\mathrm{O}$ exercício físico e a atividade de pensamento andam unidos. Assim, o ato de tentar lembrar tornar-se-ia uma atividade cansativa, mecânica e repetitiva - enfado cotidiano de qualquer um. Mas não seria uma mecânica marcada pelo círculo da regularidade. O discurso indireto livre é o aliado da dúvida na descrição sobre o que as personagens teriam pensado ou não. A memória não seria fonte para um contexto plano. No texto parece que qualquer possibilidade da redenção por uma memória coletivo-compacta estaria obliterada. O jogo entre as elucubrações subjetivas, ou melhor, a interseção entre a trivialidade subjetiva e a reunião do que pensaria cada um em um plano coletivo, não mostraria o quanto seriam artificiais e frágeis as ligações humanas?

\section{MiCROFATO COMO DISCUSSÃO DE ANTITOTALIDADE NA OBRA}

La ficción no es, por lo tanto, una reivindicación de lo falso. Aun aquellas ficciones que incorporan lo falso de un modo deliberado - fuentes falsas, atribuciones falsas, confusión de datos históricos con datos imaginarios, etcétera -, lo hacen no para confundir el lector, sino para señalar el carácter doble de la ficción, que mezcla, de un modo inevitable, leo empírico y lo imaginario. (...). La paradoja propia de la ficción reside en que, si recurre a lo falso, lo hace para aumentar su credibilidad. La masa fangosa de lo empírico y de lo imaginario, que otros tienen la ilusión de fraccionar a piacere en rebanadas de verdad y falsedad, lo le deja, al autor de ficciones, más que una posibilidad: sumergirse en ella. De ahí que la frase de 
Wolfgang Kayser: "No basta con sentirse atraído por ese acto; también hay que tener el coraje de llevarlo a cabo."3

Não estamos dizendo nenhuma novidade, tudo isso já foi muito discutido pela crítica do autor, mas acreditamos que não podemos falar de Saer sem estarmos atentos a essas proposições. Em Glosa, o grande fato é/foi uma reunião de amigos, uma festa, para comemorar o aniversário de 65 anos do historiador, antropólogo e militante de esquerda Washington Noriega. Como não é incomum em Saer, várias personagens que aparecem em outras obras do autor estão presentes também nesse “episódio”, como Carlos Tomatis, Ángel Leto, Horacio Barco, Pichón Garay etc. A própria festa ou reunião de amigos é recorrente em outras obras, como por exemplo, em El limonero real. Em Glosa, ao contrário da memória involuntária de Marcel Proust, ocorre a vontade de lembrar, o que não adianta muita coisa; já a captação da memória pelos sentidos seria dificutada. Não há recordação. Em uma longa (longa no texto) caminhada textual por San Martín, a principal avenida da cidade, Ángel Leto encontra-se com o rico Matemático, que acabara de regressar de uma viagem de turismo pela Europa e passam a tentar relembrar o acontecimento no qual não estiveram presentes. Ángel Leto não fora convidado, e o burguês Matemático (um engenheiro químico) estava em Frankfurt visitando uma fábrica no dia da festa. Assim, o diálogo entre as duas personagens é na “verdade” um confronto entre perspectivas em espiral - da perspectiva das próprias personagens e das lembranças fugazes, não lineares, fragmentárias, que tiveram da memória dos que estavam presentes. A tentativa de relembrar as versões do relato alheio não é garantia para a possibilidade da memória. Não há o resgate desse passado para essas personagens. A festa para eles é uma antifesta. Queriam muito ter estado lá.

Ocorreria uma tentativa de alegorização de diversos sentimentos das esquerdas no romance. Muitos daqueles que depois estariam mortos, desaparecidos ou exilados, aparecem na antifesta em um momento de descontração. Não estariam ali para o mal ou para o bem, e sim para uma celebração da vida no que esta teria de mais trivial e imperfeita. Intelectuais esquerdistas encontrar-se-iam não para destilar seus venenos contra a sociedade hipócrita ou defender teses contra o avanço do capitalismo selvagem, muito menos para rezar alguma cartilha de algum marxismo vulgar. (Sim, muitos fazem isso em festas!). Também não arquitetariam planos secretos e eficazes de uma tática de guerrilha armada para derrubar o poder. Os mártires ou heróis seriam humanizados. Entretanto, a alegoria aqui não teria o poder da representação e da catarse. Sua interseção com banais "sentimentos humanos”

\footnotetext{
${ }^{3}$ SAER. El concepto de ficción, p. 10.
} 
impediria o "caminho fácil do martírio e do heroísmo revolucionário”. ${ }^{4}$ O narrador contaria uma outra história, talvez uma história que muitos ainda não estejam preparados para ouvir.

O que entendemos por antifesta traz em si várias conotações que são importantes para que se compreenda o que estamos tentando dizer. A festa acontece, sim, no texto, com comidas e bebidas alcoólicas, mas de uma forma antifestiva. Para nós, a possibilidade da (grande) festa seria a redenção de toda e qualquer culpa, a compaixão pelos inocentes, a verdade em uníssono. Todos celebrando em uma só voz o conforto extático-metafísico da existência. Mas personagens principais do livro sequer compareceram para compartilhar suas ideias. María Teresa Gramuglio fala sobre essa expressão: “esas anti-fiestas desmadejadas y pobres donde nadie parece divertirse, y que suelen funcionar como un pretexto para introducir un diálogo ingenioso, que a veces bordea la parodia”. ${ }^{5}$

\section{A ANTIFESTA COMO ANTIRREPRESENTAÇÃO EM GLOSA}

A antifesta aqui poderia remontar a uma contraposição ao que se entende por "festa” desde Jean-Jacques Rousseau. ${ }^{6}$ Em Saer, o momento é oportuno para falar de reunião e união. A antifesta seria um acontecimento singular porque várias personagens que ali estiveram lutariam contra o Estado de exceção. Buscariam uma participação, mesmo que mínima, nas articulações sobre a coisa pública e se sacrificariam para isso. Mas não há uma simples relação de causalidade entre a antifesta e o futuro das personagens, apesar de o narrador, sempre incansável, persuadir o leitor a fazê-la. E por que resistir à tentação? Assumindo todos os riscos de uma amputação ou redução do que talvez quisesse dizer o narrador, percebemos a antifesta como uma antecipação ou profecia (mesmo que inconclusa e irregular) do que estaria por vir, em uma não muito nítida separação e compartimentação de diversas temporalidades. Assim, a antifesta em Saer não almejaria relacionar-se à “festa” em Rousseau, apesar de flertar com ela. E os contatos e conflitos seriam intensos, em um ato que revelaria e ocultaria ao mesmo tempo.

Outra característica da “festa” em Rousseau seria tratá-la como “metáfora da unidade da comunidade soberana. (...). Nas festas, todos agem espontaneamente, de forma

\footnotetext{
${ }^{4}$ SÜSSEKIND. Literatura e vida literária: polêmicas, diários \& retratos, p. 78.

${ }^{5}$ GRAMUGLIO. El lugar de Saer, p. 269.

${ }^{6}$ Importante defensor da democracia moderna, Rousseau é um dos críticos à representatividade na política, isto é, o ato de delegar sua participação nas decisões políticas a alguém ou a algum Estado. Para Rousseau, a corporalidade da presença seria muito marcante para o exercício da cidadania. Os cidadãos não poderiam delegar o poder político a ninguém.
} 
desinteressada, em conjunto, sem que uns ‘apareçam’ para outros, ou busquem qualquer tipo de reconhecimento". ${ }^{7}$ Nesse mesmo texto, Jean Starobinski fala da "alienação simultânea de todas as vontades” na “festa” segundo Rousseau. Não seria isto o que aconteceria em Glosa. $\mathrm{Na}$ antifesta todos agiriam interessados, mesmo que pelas coisas mais medíocres e/ou surreais e fantásticas, e entrariam em dissensão na defesa pelas coisas mais simplórias. Não poderia haver representação. Uma semente fundacional anárquica ou até mesmo a dúvida sobre a possibilidade de qualquer fundação seria colocada como contraponto a uma cega e arrebatadora paixão pelo compromisso a uma grande causa. Já que estaríamos em um tom profético, a própria dedicatória do romance já anteciparia muitas coisas. “A Michel, Patrick, Pierre Gilles, que practican tres ciencias verdaderas, la gramática, la homeopatía, la administración, el autor les dedica, por las sobremesas de los domingos, esta comedia: but then time is your misfortune father said". 8 A construção estética do narrador seria mais sofisticada do que entenderíamos como "graça” na “desgraça”. Iria além disso, mais na confecção da forma que na materialidade do conteúdo, pois o narrador procura sempre uma maneira mais inteligível, coloquial e aproximativa da vida ao discorrer sobre temas tão espinhosos quanto complexos.

Graciela Ravetti, em uma crítica mais materialista do que pretendemos fazer aqui, dialoga com Glosa lançando mão de uma esclarecedora posição sobre a crueza de práticas humanamente inaceitáveis, que rondam o universo dos guerrilheiros e de tantos outros que lutaram contra tantos desmandos. Talvez a leitura da crítica seja mais trágica que cômica, o que consegue fazer com esmero, quando por exemplo discorre sobre o suicídio (no romance o suicídio da personagem Ángel Leto) daqueles que tomaram "pastilhas” para não caírem nas garras dos torturadores e entregarem seus companheiros. ${ }^{9}$ Ravetti não descarta um "excurso" sobre a confissão como gênero para denunciar uma crítica a-histórica e somente esteticista, conivente com os ditadores. Do que já fora dito, nada a acrescentar. Tantas mortes e desaparecimentos fazem ecoar um silêncio aterrorizante que vai além de qualquer entendimento. Tentaremos aqui somente fazer com que esse "excurso" se aproxime mais um pouco dos meandros da subjetividade e da experiência, se é que isso seja possível - mesmo sabendo que a historicidade não seja um problema central no romance.

\footnotetext{
${ }^{7}$ ABREU. Representação em Rousseau e Hannah Arendt, p. 175-194.

${ }^{8}$ SAER. Glosa, p. 4.

${ }^{9}$ RAVETTI. Guerra/guerrilha na literatura latino-americana: reflexões teóricas e críticas. Glosa, de Juan José Saer e Mascaró, o caçador americano, de Haroldo Conti, p. 243-263.
} 
Impotentes para contar uma história conclusiva, seja ela qual for, os sujeitos em Glosa seriam éticos, na medida em que ainda acreditariam não na História mas na fonte dela, isto é, na ficção, e nesse caso, na ficção-poética e na imaginação, argamassas de utopias. Ravetti critica aqueles que recusam a referencialidade, sublinhando a importância do caráter político contido no texto literário. Em nosso caso, a coisas mais banais, irrisórias e cotidianas também estariam referenciadas. Em relação a quê? Poderíamos ressaltar que em relação à vida em uma gama de experiências/experimentações. A política sairia de seu caráter institucional ou oficial e se voltaria para os ranços do sujeito. Os destinos das personagens não seriam decididos apenas pelos “outros” e estes não teriam o total “poder” de vitimizá-los. Seriam também os construtores e os sujeitos de suas trajetórias, no que ela teria de mais arriscada e insólita.

Uma relação de causalidade entre texto e o duro universo dos militantes seria problematizada. O narrador não se abre para o quadro naturalista-descritivista. A memória lacunar encarrega-se de propiciar ao leitor a quase antinarração dos fatos e isenta-se de descrever as minúcias das cenas de perseguições, mortes ou torturas de perfis não exatamente heroicos. Não há uma espetacularização da dor. Muitos críticos destacam o diálogo que o texto estabelece com gêneros tão antagônicos como a comédia e a tragédia. Mas parece prevalecer alguma comiseração pela tragédia, uma vez que restaria para as personagens principais o suicídio ou o exílio. De qualquer maneira, a comédia, já marginal no texto, perderia espaço cada vez mais e de uma vez por todas no silêncio das vítimas. Alguns até dizem que ela somente apresentar-se-ia revestida pela ironia. Em nossas explanações não conseguimos perceber sucessão linear entre comédia e tragédia e a comédia permaneceria sempre, mesmo que como resto, como história.

Tornar-se-ia complicado, apesar de acreditarmos na tonalidade reforçada de uma ou de outra, preponderar a tragédia em relação à comédia, ou vice-versa, em Glosa. As personagens têm obsessão pela vida, assim como pela diversão ou pela festa. Não gastam milhares de recursos mnemotécnicos tentando resgatar o irrecuperável, mesmo que na lembrança dos outros? E o irrecuperável seria aquilo que não existirá mais. O passado seria resto, resistência, teima e labor. O encontro com ele seria o elo com a existência em usa plenitude, por isso a luta incessante em domesticá-lo. A imaginação tenta tecer no tempo espaços que não existem mais. O vazio da memória não tem o poder de apagá-la. A ordem seria para não parar, continuar a se movimentar no imponderável, ad infinitum, mesmo após a morte? A obsessão pelos fatos cômicos e triviais seria a luta presente pela permanência ou pelo que permaneceria ainda quando esses restos se misturassem com o quadro da dor e do trauma. Uma ética possível estaria em não abrir mão da imaginação. 


\section{UTOPIA DO RESGATE DO COLETIVO NA URBANIDADE ANTIFESTIVA}

Seria tarefa árdua desenhar um mapa nas páginas do livro que teria a pretensão de ter o tamanho "real" de Santa Fe. O caminhar por poucos quarteirões ocupa quase o total de páginas, porém o minucioso descritivismo, de tão fragmentado e repetitivo, faz com que tenhamos a sensação de não sair do lugar. A sensação é de desespero. Seria um chiste ao realismo-descritivismo do século 19? Ou um realismo contemporâneo? O movimento seria um antimovimento, uma antiação, um silêncio em meio a tanto barulho de uma cidade característica para pensar e imaginar uma antifesta. Cidade como impossibilidade de confinamento ao espaço. Os encontros e as conexões entre as pessoas, entre os dois caminhantes e entre quem eles encontram pelo caminho, conhecidas ou não, são por vezes fluídas, passageiras e superficiais.

Como estão no espaço da cidade, o coletivo exerce um grande fascínio sobre Leto e Matemático. A cidade seduz e convoca-os ao comparecimento, ao fazer parte. Sem perceberem, as personagens veem-se inseridas no contingente e o fixo pede passagem ao movimento. As formas ganhariam mais nitidez em sua referencialidade com os aspectos existenciais-biográficos ou sociais da narrativa e as máscaras da representação poderiam ser restituídas. Em uma "práxis dialética” (entenda-se que estamos na cidade de certa militância esquerdista), a cidade não desistiria em querer delimitar lugares. A imaginação estaria ameaçada?

Vários foram os filósofos que pensaram sobre os limites da imaginação ou sobre o colocar-se limites a ela. Imaculada Kangussu diz-nos sobre a relação entre imaginação e sublime em Kant. Em Glosa, a paixão política seduziria e arrebataria - como a materialidade da natureza sublime exigiria a entrega do sujeito para o gozo estético-abstrato. Diante do “sublime” a imaginação perderia suas forças. “A imaginação é incapaz de cumprir o que lhe é exigido: é impossível para ela encontrar no aspecto sensível do sujeito algo que o faça aparecer mais poderoso que a natureza”. ${ }^{10}$ Mas a natureza faria com que seus destinos estivessem selados de uma vez por todas? A morte não seria maior que a arte, mesmo que fosse mítica. A imaginação então “terá então que trabalhar sem imagem e procurar a 'idéia’ de uma superioridade do sujeito sobre a natureza, e esta deixa de ser onipotente pelo fato de ter sido abandonada”. ${ }^{11}$ A alegoria, a representação ou tudo o que compartimentaria o

${ }^{10}$ KANGUSSU. Walter Benjamin e Kant (I) Inexprimível: a herança do "sublime” na filosofia de Walter Benjamin, p. 153-154.

${ }^{11}$ KANGUSSU. Walter Benjamin e Kant (I) Inexprimível: a herança do "sublime" na filosofia de Walter Benjamin, p. 153-154. 
conteúdo da experiência à forma esbarraria ou tropeçaria (para usar uma imagem que o narrador usa no romance) em sua incomensurável impossibilidade. Mas ainda permaneceriam em pé. Uma outra vez que a imaginação seria colocada em prova refere-se a uma tensão maior e mais destacada desta (já que é quase ausente em Saer) com o horror da situação sociológica dos “outros” - entenda-se a luta de classes. A práxis pela qual lutariam as personagens seria colocada em xeque de uma maneira antecipatória.

Por fin encuentran un espacio lo suficientemente ancho entre dos paragolpes como para cruzar; pero se ven obligados a detenerse y a esperar, porque el grupo de la vereda de enfrente, encabezado por un hombre canoso, en mangas de camisa, que lleva un portafolios en la mano — un abogado que viene de Tribunales, casi seguro, o un alto empleado de la casa de gobierno que se dirige al centro a realizar operaciones bancarias - que ha encontrado el pasaje antes que ellos, ya ha empezado a atravesarlo en fila india. El hombre canoso sale de entre los paragolpes con la cabeza baja, perdido en sus pensamientos, llevándole cierta ventaja a sus seguidores, pero la mujer que lo sigue, un ama de casa que ha salido a hacer gestiones administrativas y que aprieta contra su pecho la libreta de familia de la que sobresale una hoja de papel sellado, les lanza una mirada que Leto, a diferencia del Matemático, bloqueado a todo comercio social, recoge al pasar con un gesto de connivencia, para tranquilizarla, porque le ha parecido vislumbrar, en la mirada de la mujer, cincuentona y redonda, de origen bastante modesto, como se dice, una especie de culpabilidad excesiva por el hecho de que ella, una simple señora de barrio, haya tenido la audacia de pasar antes que ellos dos, que parecen jóvenes cultos y de buena familia.

Leto seria assim um homo utopicus (carregado de moralidade), jamais um homo ludens. Talvez seja aí que a moral ultrapassaria a linha tênue que manteria com a ética. A lei moral prevaleceria sobre o expressar da estética. Leto parece querer ter fé e acreditar na redenção proporcionada pela política e pela razão. A “culpabilidad excesiva” presente na mulher “cincuentona y redonda, de origen bastante modesto” é a mesma de Leto, com em um espelho. Ao mesmo tempo, Leto pareceria já temer a prefiguração pela morte ou que escrevam sua história como se fosse a de um mártir. Ele parece saber que a pré-figura ou representação enquadraria ou delimitaria o desejo do encontro proporcionado pela imaginação. O humano não seria redutível ao contorno de qualquer classe e muito menos prestar-se-ia como fonte para manipulações diversas de uma história comprometida com a causa do bem contra o mal, ou vice-versa. Kangussu diz das ameaças e perigos da imaginação cair na debilidade, ao tentar sair dos contornos da razão, por isso o controle da imaginação em Kant. "É necessário modelar o elã da imaginação ilimitada para que ela, temerosa da debilidade dessa idéia, não tente representá-la em imagens através de aparatos infantis, como 
às vezes o fazem as religiões”. ${ }^{12} \mathrm{O}$ narrador não parece indiferente à filosofia sobre o sublime, porém, como não poderia deixar de ser, lança mão de todo seu aparato irônico. A leitura ética que Saer poderia fazer de Kant seria ao contrário, não almejando limitar a imaginação para que se sobressaia à racionalidade, mas discorrendo sobre os alcances da imaginação quando a racionalidade chega ao seu mais profundo vazio e sem-sentido. Imaginar demais teria o seu preço? Tanto “atrevimento” parece exigir um esforço sobre-humano para o narrador, não para que se conte uma história gloriosa e redentora, mas para o que permaneça no tempo seja o mais banal e corriqueiro, comum a qualquer humano.

La mirada de Leto trata de expresar, infructuosa, porque la señora nunca lo admitiría, el origen común de la humanidad, a partir de las llamadas ramas colaterales de ciertos primates, como les dicen, en África oriental, unos setenta millones de años atrás, en números redondos, más la idea formulada por no pocas religiones según la cual todos los seres humanos son iguales ante el sufrimiento, más su convicción personal de que la mejor organización social sería un orden igualitario, con rotación de roles, un mínimo de gobierno y socialización de los bienes de producción, pero apenas sus miradas se han cruzado una fracción de segundo, el lapso indispensable para expresar su culpabilidad a los dos jóvenes diplomados, la mujer baja otra vez los ojos, un poco avergonzada de haberse atrevido a hacerlo, confusa por la mirada connivente que le ha devuelto uno de los jóvenes, llena de sobreentendidos que ella no logra ni desea desentrañar. ${ }^{13}$

Assim, podemos pensar a antifesta, através dos lugares e espaços contidos e projetados na cidade de Santa Fe, na qual Leto e Matemático não param de caminhar. A festa seria antifesta por si só, só pelos resquícios de lembranças, ainda mais de lembranças de outros. Mas quais os resquícios daquela famigerada festa? Deixariam ou não vestígios no comportamento das personagens? O que teria ocorrido de verdade naquele aniversário? Qual o relato, se possível, original sobre este fato? Ironicamente, ou curiosamente, as personagens que lá estiveram são militantes, escritores, intelectuais, artistas. Saer insere em seus romances justamente quem tem por preocupação básica a tessitura da narrativa e suas relações com o espacejamento da vida, que pode ser estético ou político. O lugar onde ocorreu a festa, Colastiné, não é Santa Fe, a movimentada cidade onde Leto e Matemático caminhavam. Um relato dentro de outro, uma cidade dentro de outra, uma margem no interior de outra, uma vez que Santa Fe não é uma grande metrópole.

\footnotetext{
${ }^{12}$ KANGUSSU. Walter Benjamin e Kant (I) Inexprimível: a herança do "sublime” na filosofia de Walter Benjamin, p. 154.

${ }^{13}$ SAER. Glosa, p. 118-119.
} 


\section{A ANTIFESTA}

O aniversariante Washington Noriega buscava os segredos dos índios Colastinés, escrevendo trabalhos científicos. "El verano anterior, Washington se ocupaba de sus cuatro conferencias - Lugar, Linaje, Lengua, Lógica - sobre los indios Colastiné, de las que, por el momento, nadie conoce más que los títulos (...).”14 O narrador ironizaria na ação ou antiação dessa personagem o próprio fazer historiográfico, isto é, a confecção da história. No entanto, o mais interessante seria salientar como viveriam os historiadores e antropólogos em sua intimidade e o que aconteceria nos bastidores, quando estão apreensivos escrevendo seus textos, que serão depois a palavra final sobre determinado assunto. Pensariam o tempo todo na real possibilidade de narrar o passado, de capturar objetivamente o fato ocorrido? Seriam tão oficialescos ao escreverem como em uma festa?

Na antifesta, o discurso do conferencista é prosaico e monótono, distante de qualquer epopeia. Já não interessa saber quem foram os índios Colastinés, ou algo parecido. Em uma dose de humor, altamente irônica, os quiproquós sobre o fato de que um cavalo seria capaz ou não de tropeçar, ou sobre a situação existencial de mosquitos, valeriam mais a pena. Esta é a memória que Leto e Matemático querem resgatar; estas discussões foram o que de principal teria acontecido na tal festa de aniversário. Não há somente a impossibilidade de narrar o épico, mas o mais banal. É importante declarar que uma das tensões presentes no romance revela-se nessas ponderações - o mais elegante dos animais ao mais insignificante dos insetos.

“Pensándolo bien, nadie dice los mosquitos, todos dicen el mosquito, como si fuera siempre el mismo y como si, por medio de esa sinécdoque, que le dicen, se tratara de escamotear o, quizás, al contrario, de sugerir, el problema fundamental: ¿uno o muchos?”15 Porém, não nos deixemos enganar, a insignificância dos mosquitos não oculta as possibilidades das configurações estéticas. Assim como os mosquitos de Washington Noriega, poderíamos sobreviver à homogeneização e ao achatamento do discurso autoritário, mesmo que este seja o discurso da esquerda. Afinal de contas, os mosquitos são basicamente de três tipos. “(...) uno que no se aventura uno que se aventura y que levanta vuelo y se va cada vez que la mano sube para aplastarlo, y uno que a la primera tentativa nomás se deja aplastar contra la mejilla.”16

\footnotetext{
${ }^{14}$ SAER. Glosa, p. 60.

${ }^{15}$ SAER. Glosa, p. 66-67.

${ }^{16}$ SAER. Glosa, p. 81.
} 
A antifesta seria sobretudo uma discussão sobre pontos de vista muito diversos na qual percebemos rixas e tensões. Não poderíamos deixar de mencionar que preocupações humanistas são jogadas na roda. Intelectuais e não biólogos preocupam-se com bichos (seres humanos?) e fazem discursos ${ }^{17}$ sobre estes, sobre algo que não dominam e que já está distante no tempo. Leto e Matemático querem posturas sobre uma discussão sobre cavalos e mosquitos, impossível de ser apreendida, o que chega ao absurdo e ao fantástico, porque nem os que lá estiveram conseguiram chegar a um consenso.

(...) Que como se habían puesto a delirar sobre un caballo por qué no deliraban ya que estaban sobre tres mosquitos, de manera tal que, puesto que se les había dado por delirar, deliraran en serio, no a costa de un pobre caballo sobrecargado desde el vamos de delirio insensato por la especie humana, sino, si eran capaces, y ya que tanto les gustaba delirar, de tres mosquitos, grises, diminutos y neutros, un modo elegante de sugerirles que, cuanto más cuanto más irrisorio es el objeto, más claro resulta el tamaño del delirio. $^{18}$

Não é somente nesse ponto que ocorre tensões e conflitos entre discursos em Glosa. As personagens Leto e Matemático revelam sua vertente mais patética. Até onde chegaria o compromisso com a grande causa? Até onde haveria a possibilidade desse contraponto? Enquanto tentam descrever a festa de Washington, Leto e Matemático relembram seu próprio passado, o que não é uma tarefa agradável, pois flashs de restos do que já foi parecem querer uma continuidade com o presente deles. Aqui a impotência não seria em relação à lembrança e sim em relação ao esquecimento. Leto e Matemático não conseguem apagar o ressentimento que sentem por seu passado. Leto, de família mais modesta, viveu o suicídio de seu pai, trauma que não conseguiu vencer, pois terá o mesmo fim ao tomar as famosas pastilhas de veneno, para que não seja apanhado pelos torturadores e corra o risco de entregar seus companheiros. Leto também sente certa inveja de Matemático, de suas viagens pela Europa, de suas roupas e sua condição aburguesada. O relato de Leto sobre as cidades que Matemático visitou é uma repetição incessante das mesmas palavras, o mesmo acontece quando descreve suas nobres vestimentas e elegantes sapatos. "De Matemático, não?”

Matemático, por sua vez, tem outras impotências. É obcecado e pensa o tempo todo no conhecimento, no saber, na fórmula fácil. Seu ressentimento maior seria por não conseguir

\footnotetext{
${ }^{17}$ Entende-se aqui discurso como o oposto de narrativa, tal qual formula Saer, porém não esqueçamos de que esses discursos são projetos de um narrador maior que garantiria, ao mesmo tempo, a impossibilidades desses discursos e a alimentação e renovação incessante da materialidade ficcional-artística.

${ }^{18}$ SAER. Glosa, p. 81.
} 
alcançá-los. Sua condição burguesa parece uma bricolagem de uma outra realidade exposta e sem-lugar no texto. Sua condição socioeconômica seria um diferenciador marcante, pois no fundo no fundo, não queriam todos eles a "Revolução”? Nossos heróis, ou anti-heróis em Glosa são seres comuns, destituídos de qualquer composição aurática. Não conseguem sair de sua condição humana. Um ar de impossibilidades rodeia-os o tempo todo.

Sin darse cuenta, Leto, que, no sabiendo qué hacer, lleva la mano al bolsillo
de su camisa para sacar los cigarrillos, siente que, por alguna razón, él está
excluido de muchos mundos que el Matemático frecuenta, que el
Matemático es una especie de ente solar perteneciente a un sistema en el que
todo es preciso y luminoso y que él, en cambio, chapotea en una zona
viscosa y nocturna, de la que rara vez puede salir, en tanto que el
Matemático, a pesar de su cabeza elegante llena de recuerdos recientes y
coloridos de Viena, Amsterdam, Cannes, Málaga y Spoleto, siente haber
estado desterrado en las tinieblas exteriores durante tres meses y que Leto,
Tomatis, Barco, los mellizos Garay y todos los otros, han aprovechado su
ausencia para darse la gran vida en la ciudad. ${ }^{19}$

Leto deveria ou não ter tomado tais pastilhas? O exílio seria a melhor saída para Matemático, uma vez que poderia, se quisesse, aceitar sua condição burguesa e conformar-se com o sistema? Curiosamente, o futuro das personagens aparece na narrativa saeriana, o que não tem continuidade com o restante da trama. Leto fica com a morte trágica no final do livro, e Matemático (não no final do livro) vai para o exílio na Europa, depois de se casar com uma mulher "baja, gorda, fea, judía, feminista, trotsquista y viuda de un trotsquista"20 (tudo o que a família não esperava dele), que acaba desaparecida pela repressão política. A ficção de Saer não nos dá muitas respostas. O que teria realmente acontecido?

Entretanto, sua força e riqueza não estão aí. Estaria em mostrar a fragilidade da condição humana e os silêncios do testemunho de quem já vivenciou o horror? Acreditamos que a ética-estética em Glosa estaria na tentativa de se aproximar de algum discernimento do que a imaginação seria possível. Fica a pergunta: Será que Matemático e Leto não foram a tal festa propositadamente, só para serem personagens de uma ficção sobre a impossibilidade da memória? Meras suposições... Afinal, elas não são personagens da Zona, onde tudo é possível? Nas im-possibilidades narrativas de Saer, um mosquito no calor do verão poderia, afinal de contas, escapar de ser achatado pela palma de uma mão. Fiquemos com a crítica de Saer:

\footnotetext{
${ }^{19}$ SAER. Glosa, p. 14.

${ }^{20}$ SAER. Glosa, p. 88.
} 
Es abriendo grietas en la falsa totalidad, la cual no pudiendo ser más que alienación e ideología, que la narración destruirá esa escarcha convencional que se pretende hacer pasar por una realidad unívoca. (...). Que nuestro lector sea como el hombre que, encaminándose maquinalmente hacia una catástrofe oye, repetidas veces, y desde la oscuridad, un llamado, que lo inquieta, lo desvía, lo demora, y le hace, por fin, cambiar la dirección de su marcha para dedicarse a buscar, en la oscuridad, la fuente de la que ese llamado puede provenir - sin que tenga que haber, necesariamente, en algún lugar de la oscuridad, una fuente. ${ }^{21}$

\begin{abstract}
The antiparty in Saer would be utopia of the memory of an anticipatory moment of what would be to come. There leftists and future guerrillas would show their fears and desires for the most banal and prosaic. This is the story that Leto and Matemático can not recover, but it is going to mark them as rests and possibilities of the experience.
\end{abstract}

\title{
KEYWORDS
}

Memory, ethics, politics, aesthetics, guerrilla

\section{REFERÊNCIAS}

ABREU, Maria Aparecida Azevedo. Representação em Rousseau e Hannah Arendt. Lua Nova, São Paulo, n. 72, p. 175-194, 2007.

GRAMUGLIO, María Teresa. El lugar de Saer. In: LAFFORGUE, Jorge (Ed.). Juan José Saer por Juan José Saer. Buenos Aires: Celtia, 1986. p. 261-299.

HUIZINGA, Johan. Homo ludens. 4. ed. Trad. João Paulo Monteiro. São Paulo: Perspectiva, 2000.

KANGUSSU, Imaculada. Walter Benjamin e Kant (I) Inexprimível: a herança do "sublime” na filosofia de Walter Benjamin. In: SELIGMANN-SILVA, Márcio (Org.). Leituras de Walter Benjamin. 2. ed. São Paulo: Fapesp: Annablume, 2007. p. 151-160.

SAER, Juan José. Glosa. Buenos Aires: Seix Barral, 1995.

SAER, Juan José. El concepto de ficción. In: . El concepto de ficción. Buenos Aires: Planeta, 1997. p. 9-17.

SAER, Juan José. Narrathon. In: . El concepto de ficción. Buenos Aires: Planeta, 1997. p. $145-158$.

SAER, Juan José. La narración-objeto. In: . La narración-objeto. Buenos Aires: Planeta, 1999. p. 15-29.

\footnotetext{
${ }^{21}$ SAER, Juan José. Narrathon, p. 158.
} 
SARLO, Beatriz. Narrar la percepción. In: Escritos sobre literatura argentina. Buenos Aires: Siglo XXI, 2007. p. 281-285.

SÜSSEKIND, Flora. Literatura e vida literária: polêmicas, diários \& retratos. 2. ed. Belo Horizonte: Editora UFMG, 2004.

RAVETTI, Graciela. Guerra/guerrilha na literatura latino-americana: reflexões teóricas e críticas. Glosa, de Juan José Saer e Mascaró, o caçador americano, de Haroldo Conti. In: CORNELSEN, Elcio; BURNS, Tom (Org.). Literatura e guerra. Belo Horizonte: Editora UFMG, 2010. p. 243-263. 